\title{
Irrigation Scheduling Using Soil Moisture Sensors
}

\author{
Ruixiu Sui ${ }^{1}$ \\ ${ }^{1}$ USDA-ARS Crop Production Systems Research Unit, Stoneville, Mississippi, USA \\ Correspondence: Ruixiu Sui, USDA-ARS Crop Production Systems Research Unit, Stoneville, Mississippi, \\ USA. Tel: 1-662-686-5382. E-mail: ruixiu.sui@ars.usda.gov
}

$\begin{aligned} & \text { Received: September 10, } 2017 \quad \text { Accepted: October 20, 2017 Online Published: December 15, } 2017 \\ & \text { doi:10.5539/jas.v10n1p1 }\end{aligned}$ URL: https://doi.org/10.5539/jas.v10n1p1

\begin{abstract}
Irrigation is required to ensure crop production. Practical methods of use sensors to determine soil water status are needed in irrigation scheduling. Soil moisture sensors were evaluated and used for irrigation scheduling in humid region of the Mid-South US. Soil moisture sensors were installed in soil at depths of $15 \mathrm{~cm}, 30 \mathrm{~cm}$, and $61 \mathrm{~cm}$ belowground. Soil volumetric water content was automatically measured by the sensors in a time interval of an hour during the crop growing season. Soil moisture data were wirelessly transferred onto internet through a wireless sensor network (WSN) so that the data could be remotely accessed online. Soil water content measured at the three depths were interpreted using a weighted average method to reflect the status of soil water in plant root zone. A threshold to trigger an irrigation event was determined with sensor-measured soil water content. An antenna mounting device was developed for operation of the WSN. Using the antenna mounting device, the soil moisture measurement was not be interrupted by crop field management practices.
\end{abstract}

Keywords: irrigation scheduling, soil moisture sensor, soil water content, wireless sensor

\section{Introduction}

The United States (US) is among the top 5 cotton producing countries and the largest cotton exporter in the world (USDA, 2017). Most of cotton in US is grown in a region known as the cotton belt which includes humid regions in the Mid-South US. Though annual precipitation in the Mid-South US is approximately $130 \mathrm{~cm}$, only about $18 \%$ of the precipitation occurs during June to August when crops require a large quantity of water to grow. Furthermore, heavy rainfall in summer causes extensive amounts of runoff, resulting in only a small amount of the precipitation infiltrating into the soil for crop use. Uncertainty in the amount and timing of precipitation is one of the most serious risks to crop production in the region. To reduce the risk and increase farming profit, irrigation acreage in the Mid-South has being increased in recent years. More than $90 \%$ irrigation water in the region is groundwater from Mississippi River Valley alluvial aquifer (Byrd, 2011). Due to the large withdrawals water levels of the aquifer have significantly declined across the region. Reports from Yazoo Mississippi Delta Joint Water Management District showed that the aquifer level in Sunflower County of Mississippi Delta dropped $655 \mathrm{~cm}$ from 1994 to 2014 (YMD, 2014). In 2015, the level declined $13.7 \mathrm{~cm}$ across the Mississippi Delta region (YMD, 2015). Ongoing depletion and stagnant recharging of the aquifer jeopardize the long-term availability of the aquifer and place irrigated agriculture in the region on an unsustainable path. Local governments, organizations, and producers in the region are realizing the necessity of seeking improved irrigation technologies to increase water use efficiency for sustainable use of water resources. Common method used in irrigation scheduling in this region is based on visual assessment of crop response and a "feel" for soil water status. There is a great need for the producers to have objective, reliable, and easy-to-use water management technologies that work for the Mid-South crop and soil environments.

Producing high-yielding and high-quality cotton requires careful management in every production stage, including field management practices in irrigation. Water-stress in cotton plants can limit plant growth and productivity, resulting in reduction of yield (Cull, Hearn, \& Smith, 1981). Pettigrew (2004) studied the effects of moisture deficit stress on cotton lint yield and fiber quality and reported that compared with irrigated plants, dryland plants under water stress reduced lint yield by $25 \%$. Irrigated plants produced more bolls and approximately $2 \%$ longer fiber than the dryland plants. Balkcom et al. (2006) found that irrigation improves ginning percentage and increased yield, and fiber quality parameters such as the length, micronaire, and uniformity were affected by the irrigation regimes. Basal et al. (2009) reported cotton fiber length was reduced in 
response to soil moisture deficits. Sui et al. (2017) reported that supplemental irrigation increased lint yield by $26 \%$ and fiber length by $2 \%$, and improved plant capability in utilizing the applied $\mathrm{N}$ fertilizer.

Irrigation scheduling determines the time and amount of water to apply. Irrigation events can be scheduled based on 1) soil moisture content in plant root zone, 2) the amount of water lost by plant evapotranspiration (ET), and 3) plant response to water stress. Compared to the other two methods, the soil moisture-based irrigation scheduling method is easier to implement (Henggeler et al., 2011). This method determines when and how much water to apply using the amount of available water to the plant from soil. However, although soil moisture can be determined using manual gravimetric soil sampling by weighing and drying the soil sample, the process could be time consuming and expensive as frequent measurements are required. In recent years, various types of soil moisture sensing devices have been developed and are commercially available for measuring soil moisture. Some of these devices are capable of wirelessly transferring the data collected from their sensors.

Evaluations have shown that each type of soil moisture sensing devices has its advantages and shortcomings in terms of accuracy, reliability, and cost (Basinger et al., 2003; Chanzy et al., 1998; Evett \& Parkin, 2005; Seyfried \& Murdock, 2004; Yao et al., 2004). The neutron probe has been shown to be a reliable tool for determining soil water content (SWC). However, its use of radioactive source, the maintenance requirement, and the cost have restricted its application in recent years. Meanwhile, electromagnetic (EM) sensors, such as electrical capacitance and resistance type sensors, and time-domain reflectometer (TDR) devices have been rapidly developed and adopted for soil-water measurement (Dukes \& Scholberg, 2004; Fares \& Alva, 2000; Miranda et al., 2005; Seyfried \& Murdock, 2001; Vellidis et al., 2008). Research shows that soil moisture sensors could be used as an irrigation tool for saving water. However, procedures for proper installation, calibration and maintenance of soil moisture sensing devices are critical for the success of soil moisture sensor-based irrigation scheduling (Yoder et al., 1997; Leib et al., 2003; Evett et al., 2006; Sui et al., 2013).

The objective of this study was to develop a practical method to use soil moisture sensor for irrigation scheduling in cotton.

\section{Materials and Methods}

\subsection{Site and Devices}

A soil moisture sensing system for irrigation scheduling was implemented in a cotton field at a Research Farm of USDA-ARS Crop Production Systems Research Unit at Stoneville, Mississippi, USA. Soil type of the field varied from silt to silt loam. The field was approximately 7.5 ha and under coverage of a center pivot irrigation system. Experimental plots with irrigated and rainfed regimes were employed in the field for irrigation management study.

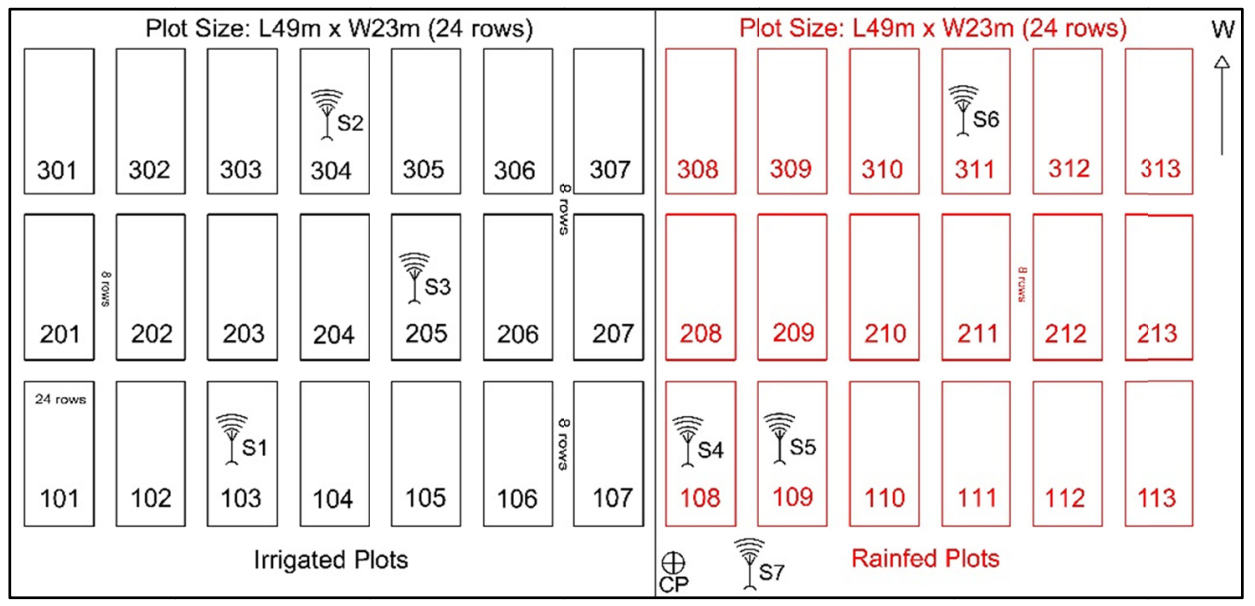

Figure 1. Cotton field layout of the soil moisture sensors in 2015 and 2016. S1-S6 are the sensor locations while $\mathrm{S} 7$ is the data station near the center pivot (CP)

In both 2015 and 2016 season, cotton cultivar FM1944GLB2 was selected and planted in the field on May 5. Nitrogen fertilizer at the designated rate was applied as a urea-ammonium nitrate solution (N-sol, 32\%) to each plot with a side knife drill 48 days after planting (DAP) in 2015 and 49 DAP in 2016. Insects and weeds in the 
plots were controlled with generally recommended procedures in the region throughout the growing seasons. In 2015, defoliation was initiated on Sept. 8 and Sept. 15 in rainfed and irrigated plots, respectively. Cotton in rainfed and irrigated plots was machine harvested with a spindle-type picker on Sept. 24, and Oct.7, respectively. For 2016 season, all plots were defoliated on Sept. 13 and machine picked on Oct. 4.

The soil moisture sensing system included soil volumetric water content sensors (EC5, GS1, Decagon Devices, Pullman, WA), two models of data loggers (EM50R and EM50G, Decagon Devices) and a data station (ECH2O $900 \mathrm{MHz}$, Decagon Devices) for data acquisition, and a measurement and control data logger (MCDL) (CR1000, Campbell Scientific, Logan, UT) coupled with a wireless modem (RavenXTG, Sierra Wireless, Carlsbad, CA) for data collection and transmission (Sui \& Baggard, 2015). EC5 and GS1 SWC sensors were used with the data logger EM50R and EM50G to measure soil volumetric water content. EC5 sensor and GS1 sensor are made with same measurement principle and by the same manufacture (Decagon Devices, Pullman, WA). Both models are capacitance-based soil moisture sensors while the GS1 is more physically robust than the EC5 (Figure 2). The EM50R logger used a $900-\mathrm{MHz}$ frequency radio to transmit data to the data station. After the data were automatically downloaded from the data station to the MCDL, the wireless modem automatically transmitted all data through a commercial wireless network to make the data accessible on the internet using a LoggerNet data logger support software (Campbell Scientific, Logan, UT). In the EM50G logger system, data were transmitted through a cellular communication network to a service which made data available on the internet. A software from Decagon was used to download the data and display the soil moisture graphics. Both EM50G and EM50R loggers had the capacity to collect data from up to five sensors. In this study three SWC sensors were used with one data logger.

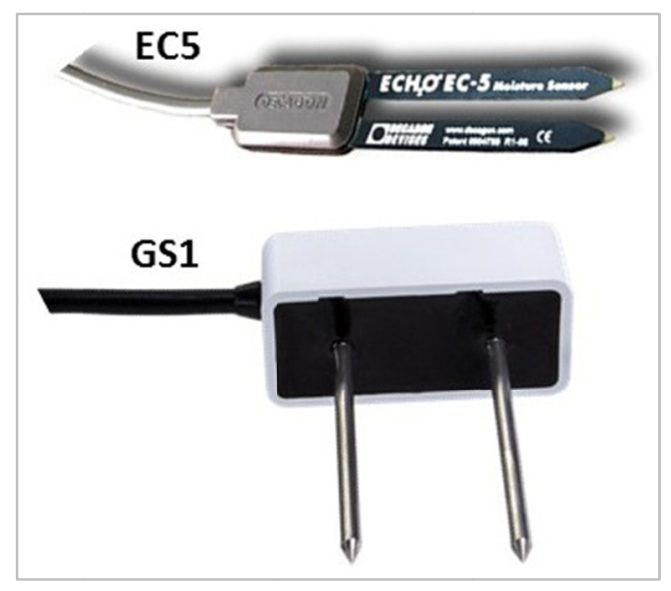

Figure 2. EC5 and GS1 soil water content sensors

\subsection{Sensor Calibration}

The SWC sensors were evaluated and calibrated using a weighing method. Five 2-Gallon soil pots were filled with soils from the field where the sensors were installed. Dry matter and bulk density of the soil in the pot were determined. One EC5 sensor was horizontally placed at the center of each soil pot. After the soil in pot was saturated with water, the pot with the sensor was placed on an electronic scale (HD-150, My Weight, Phoenix, AZ) to continuously measure the weight. Meanwhile, the sensor continuously measured the SWC. The SWC in the pot was calculated using the scale-measured weight and the known soil dry matter and bulk density. Scale-measured water content was then compared with the sensor-measured water content for the sensor calibration.

\subsection{Sensor and Logger Installation}

The sensors were installed in field at depths of $15 \mathrm{~cm}, 30 \mathrm{~cm}$, and $61 \mathrm{~cm}$, respectively. To install the sensors, a hole was drilled at the center of the crop row using a soil auger. The soil moisture sensors were inserted horizontally into the soil at the designated depths (Figure 3). EM50G data loggers were mounted on a wooden stake and installed beside the plants in the row. The antenna of these EM50G loggers was about $30 \mathrm{~cm}$ above the ground. EM50R loggers were also installed using a similar method as the EM50G loggers in field. However, their antennas were placed about $1.8 \mathrm{~m}$ above the ground using the antenna mount device described as below. The 
sensors were connected to the logger using cables. All loggers were set up to continuously make one measurement of SWC in every minute. Hourly average of the measurements was calculated and wirelessly reported at a time interval of one hour. The data are available online for download and process.

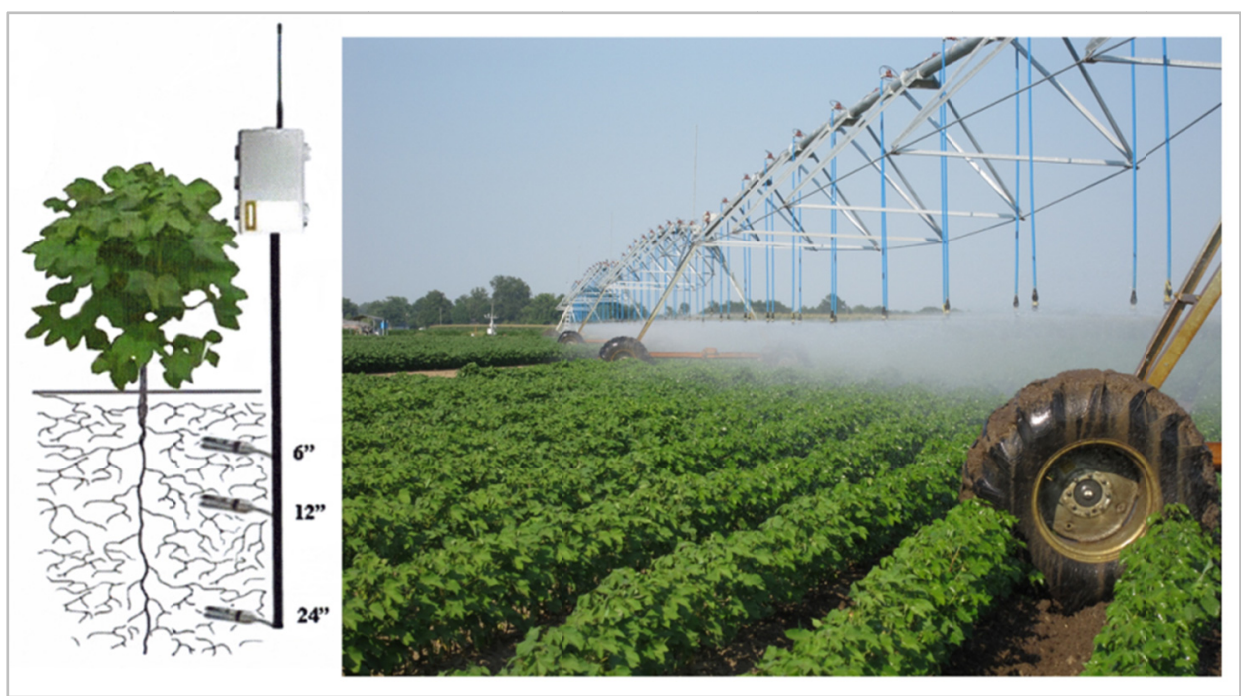

Figure 3. Illustration of Soil moisture sensors installed in three depths across the root zone (left). Irrigation scheduled based on soil moisture measured by soil water sensors (right) (photograph by Ruixiu Sui)

It was found that data transmission of EM50R logger was affected by plant canopy (Sui \& Baggard, 2015). Data could not be properly transmitted when plant canopy was higher than the antenna of EM50R logger. To use a pole to place the antenna to a higher position could eliminate this issue. However, the antenna poles in field will obstruct normal operation of the equipment such as sprayers. To make the wireless sensor more practical for field use, an antenna mount was developed for EM50R data logger (Figure 4). The antenna mount includes a spring (SSM-3, Hustler/New-Tronics Antenna Corp., Mineral Wells, TX), a U-shaped metal base, and a PVC pipe. The spring was mounted between the center of the U-shaped base and one end of the pipe. The U-shaped base was made of a steel strip of $6 \mathrm{~mm}$ thick and $51 \mathrm{~mm}$ wide. The base was $28 \mathrm{~cm}$ tall and $30 \mathrm{~cm}$ wide with two sharp ends for insertion into the ground. The PVC pipe was $1.8 \mathrm{~m}$ long and $25 \mathrm{~mm}$ in diameter. There are threads at both ends of the spring. A threaded rod was used to connect the PVC pipe and spring. A hole was drilled through the pipe and the rod, and the pipe and rod was tied up using a screw. At another end of the spring, a screw was used to join the spring and the base together. A hole was drilled in the pipe at about $30 \mathrm{~cm}$ from the spring-pipe joint for pulling antenna cable inside the pipe for cable protection. The antenna connected to the cable was installed inside the top end of the pipe. In use of the mount in field, the U-shaped base was inserted into the soil, and the antenna cable was connected to the wireless device (Figure 4). As the agricultural equipment passed over the wireless device and impacted the PVC pipe, the spring in the mount would be bent and the antenna inside the PVC pipe would be protected from damage. After the equipment passed through, the spring would make the PVC pipe with the antenna back to an upright position again. 

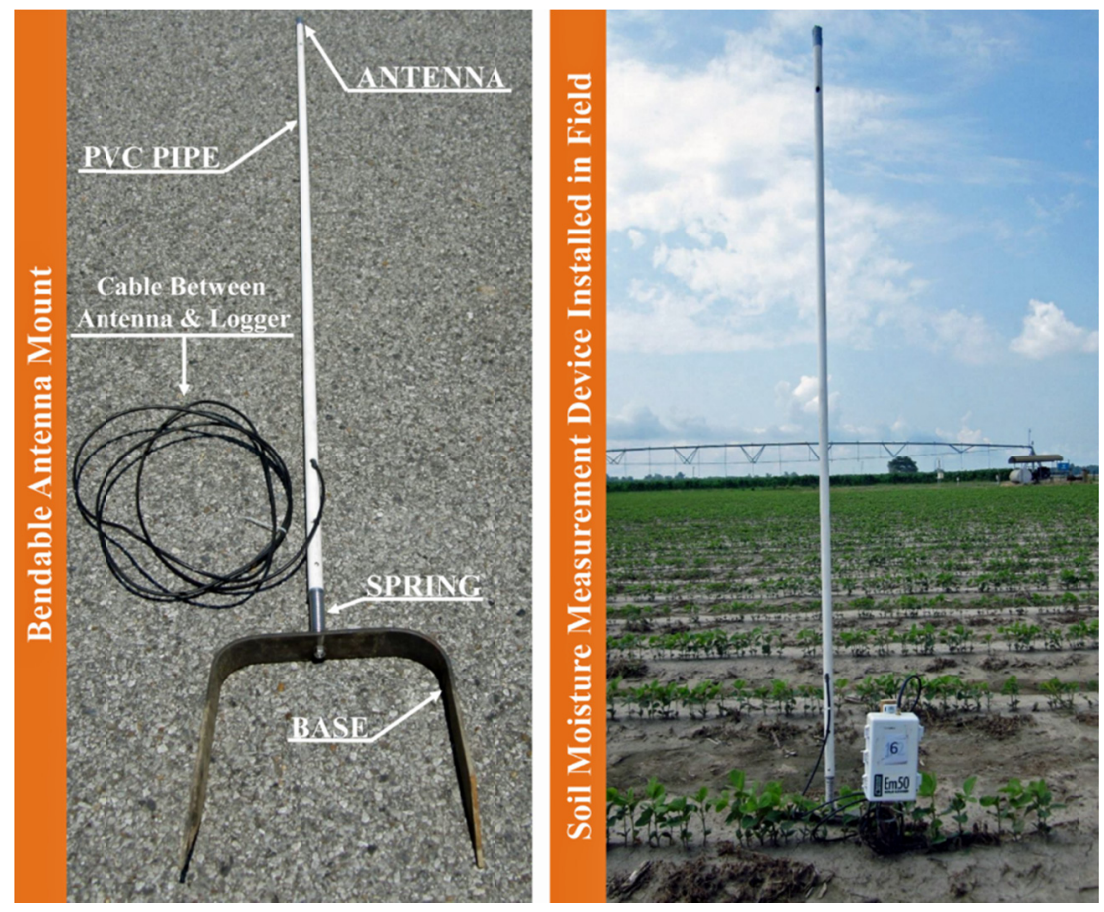

Figure 4. Bendable antenna mount device (left) and its field installation with an EM50R data logger (right).

(Photographs by Ruixiu Sui)

\section{Results and Discussion}

\subsection{Sensor Calibration}

Readings from the sensors have a linear correlation with the scale-measured SWC (Figure 5). The sensors over-estimated the water content when the manufacture's "mineral soil" calibration was used. The relationship between sensor-measured SWC and scale-measured SWC was used in the sensor calibration. Figure 6 showed the sensor-measured SWC and the scale-measure SWC as the SWC varied in a range from $13 \%$ to $38 \% \mathrm{~m}^{3} / \mathrm{m}^{3}$. It was indicated that the sensor had a better measurement accuracy with higher SWC. As the water content decreased, the difference between the sensor-measured SWC and the scale-measured increased. In general, the sensors were capable of detecting general trend of soil-water changes. However, their measurements varied among the sensors and were influenced by soil texture (Sui et al., 2013). To obtain accurate measurements, the sensors require soil-specific calibration. 


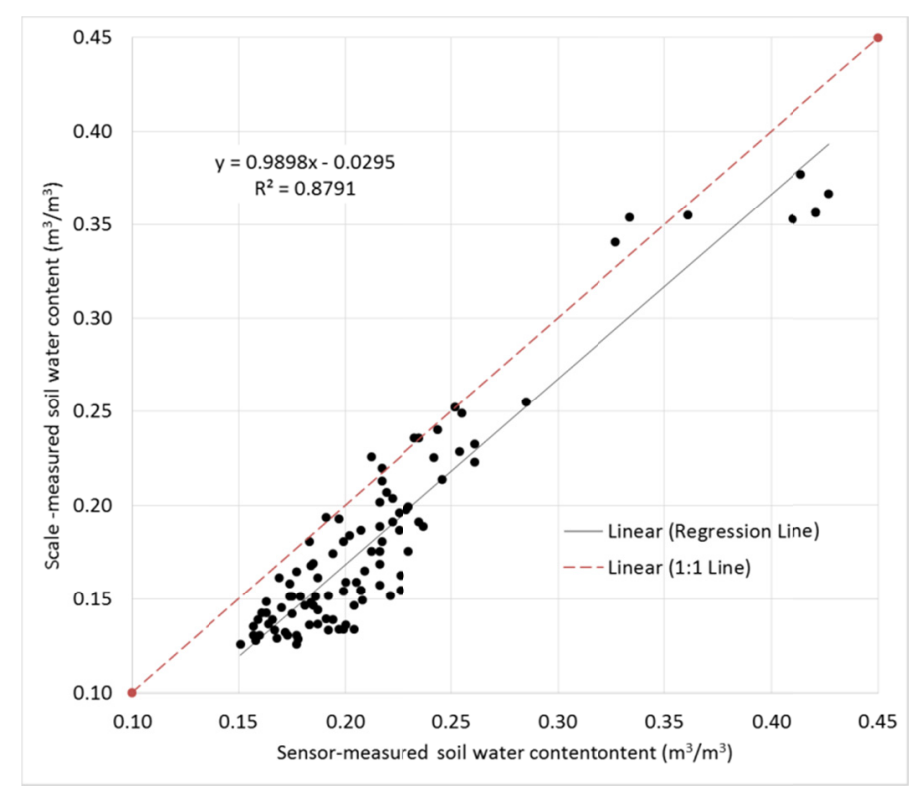

Figure 5. Sensor-measured SWC versus scale-measured SWC

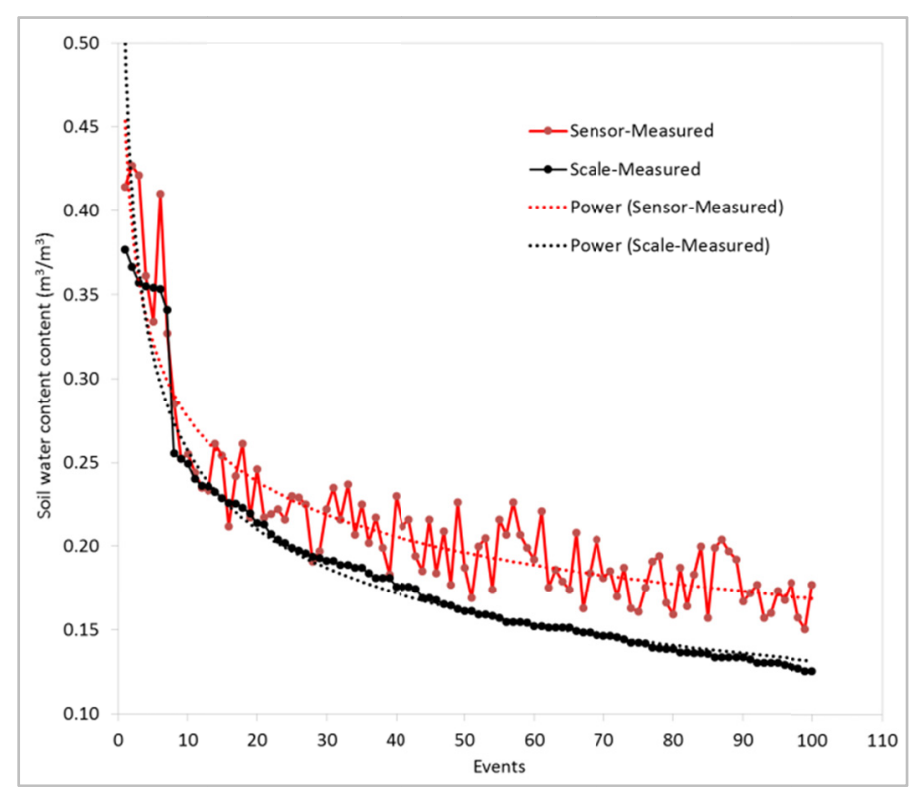

Figure 6. Comparison of sensor-measured SWC with the scale-measured

\subsection{Data Processing and Application}

This soil moisture sensing system has been used in this field since 2012. As an examples, sensor-measured SWC in 2015 and 2016 season was shown in Figure 7 and 8, respectively. Weighted average of the sensor measurements at three depths was calculated for irrigation scheduling. According to plant root distribution, the weight assigned to the measurement at depth of $15 \mathrm{~cm}, 30 \mathrm{~cm}$, and $61 \mathrm{~cm}$ was $0.45,0.35$, and 0.2 , respectively. The weighted average measured by the sensors at 48 hours after the soil was saturated was used as the sensor-measured field capacity (FC). Irrigation event was triggered when percent plant available water (PPAW) dropped approximately to 50\%. PPAW was calculated using Equation 1.

$$
\text { PPAW }=\frac{\text { Sensor-measured SWC }- \text { SWC at wilt point }}{\text { Field Capacity }- \text { SWC at wilt point }}
$$


This soil moisture sensor-based irrigation scheduling method has been used in cotton. In general, it worked fairly well. However, it has been observed that the weights assigned to the measurement at different depths and the threshold to trigger an irrigation event should be adjusted according to crop growth stages due to the difference of crop root distribution patterns in the soil profile.
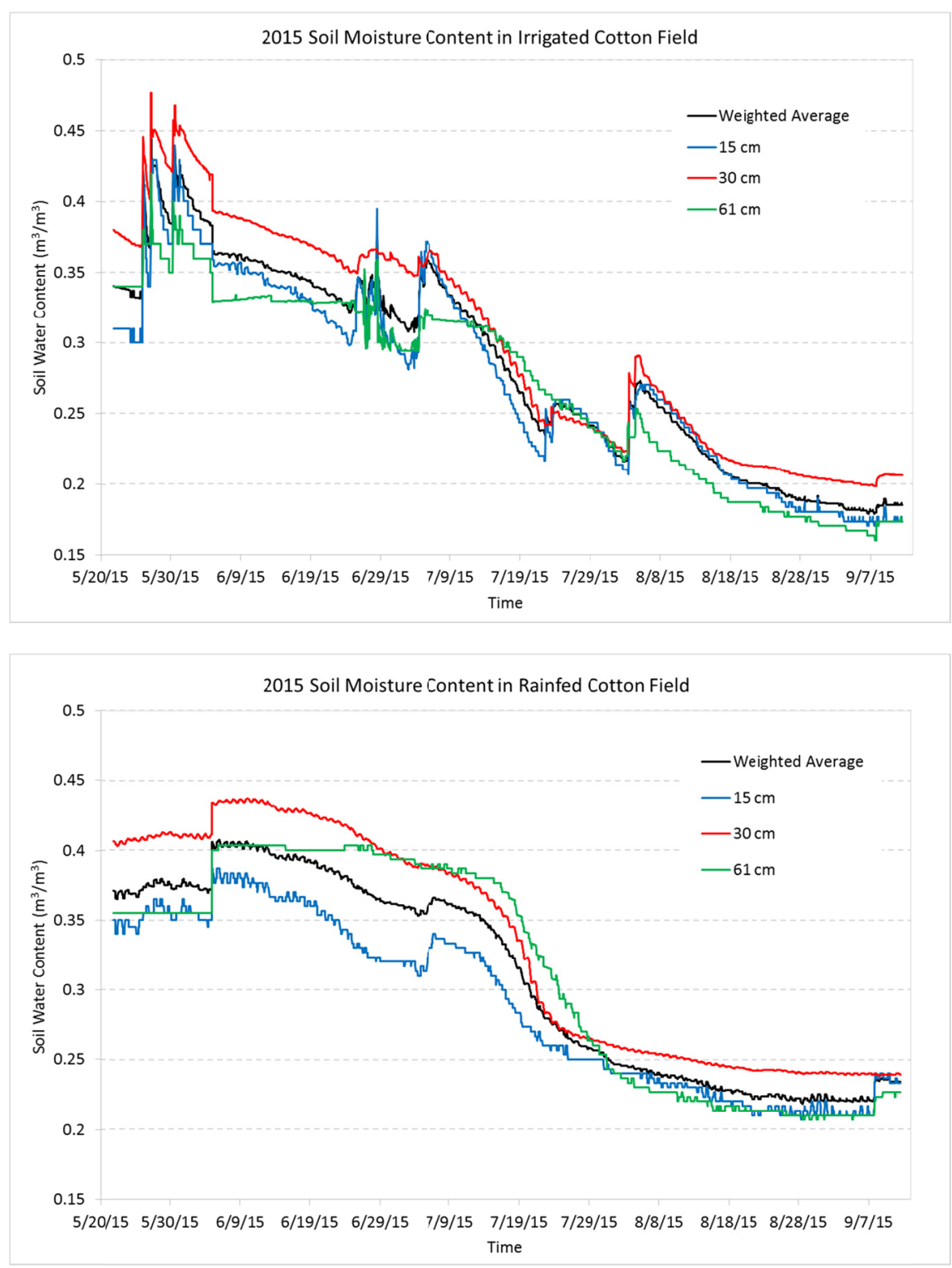

Figure 7. SWC in the irrigated plot and rainfed plot in 2015 

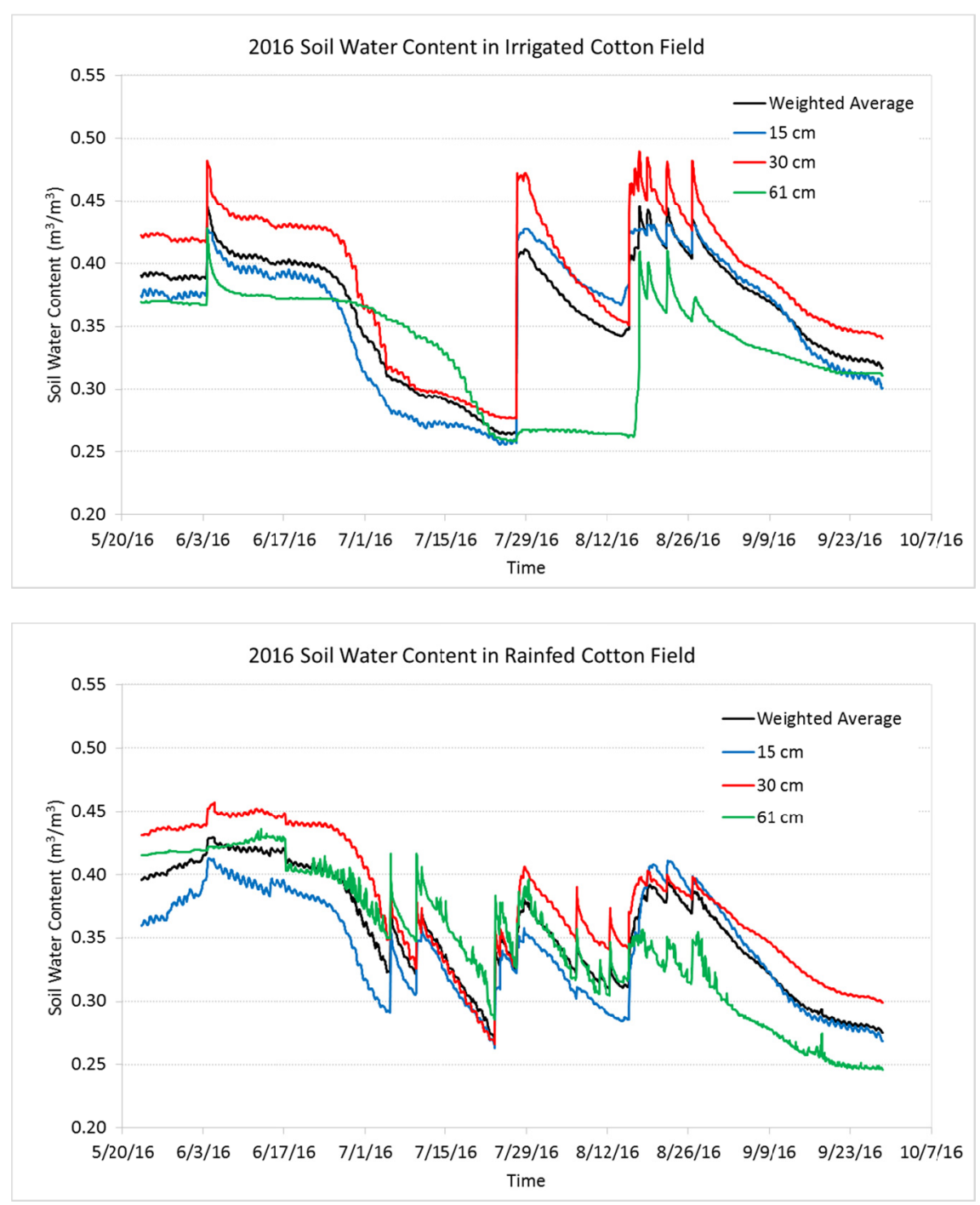

Figure 8. SWC in the irrigated plot and rainfed plot in 2016

Figure 9 and 10 illustrate the rainfall distribution and irrigation events during cotton growing season in 2015 and 2016. In 2015, the total amount of precipitation during the season from May 5 to Oct. 1 was $34.3 \mathrm{~cm}$. Six irrigation events were scheduled with a total water depth of $15.2 \mathrm{~cm}$ applied. 2016 was a wet year. $50.6 \mathrm{~cm}$ rainfall was received during the cotton growth season from May 5 to Oct. 5. Due to large amount of rainfall, only two irrigations were conducted with total water depth of $3.2 \mathrm{~cm}$ applied in 2016.

\subsection{Installation and Maintenance}

The sensor installation and maintenance are critical in application of soil moisture sensors. The sensors should be installed in a representative area of the field. In installation, it needs to make the sensor prongs contact the soil well, and minimize the disturbance of the soil profile. The sensor should be installed on crop row, and the plants near the sensing location should not be damaged during sensor installation and maintenance. After growing season, the loggers can be disconnected from the sensors and removed from field, the sensor can remain in the soil for use in next season. However, attention should be given to prevent the sensor from being damaged in field practices such as subsoil tillage. The section of sensor cable above the ground could be damaged by wild animals in field. It needs to be protected using physical or chemical means (e.g., flexible aluminum conduit or spray). The bendable antenna mount has been used in field operation. It was capable of protecting the antenna from damage by the equipment and positioning the antenna above plant canopy for wireless signal transmission. 


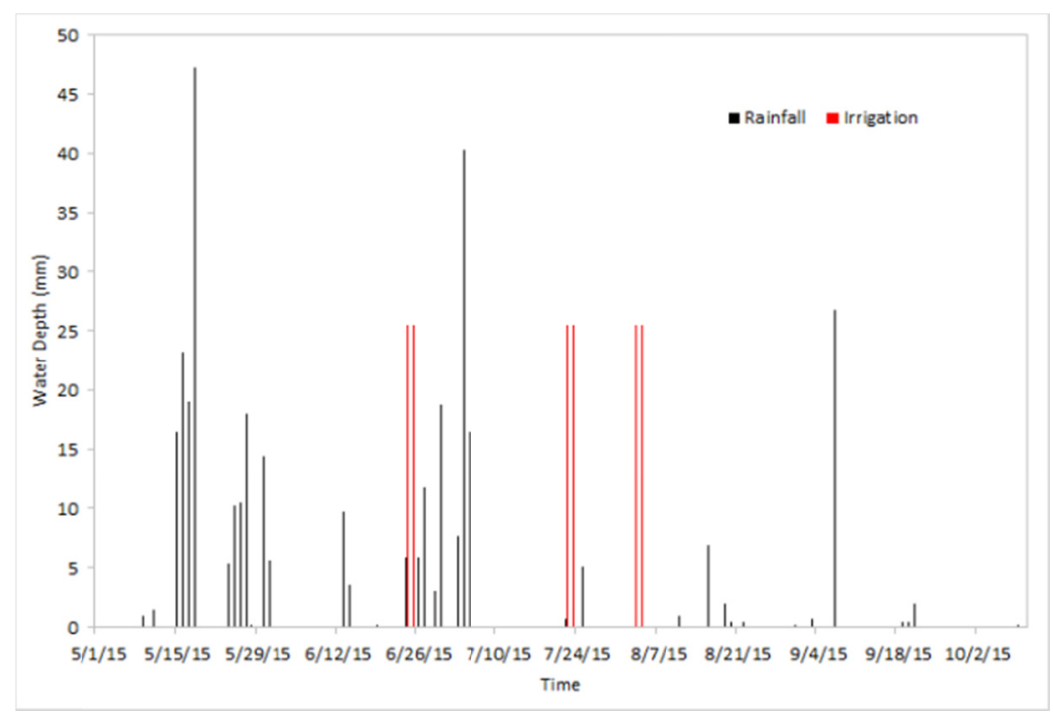

Figure 9. Rainfall distribution and irrigation events in 2015 season

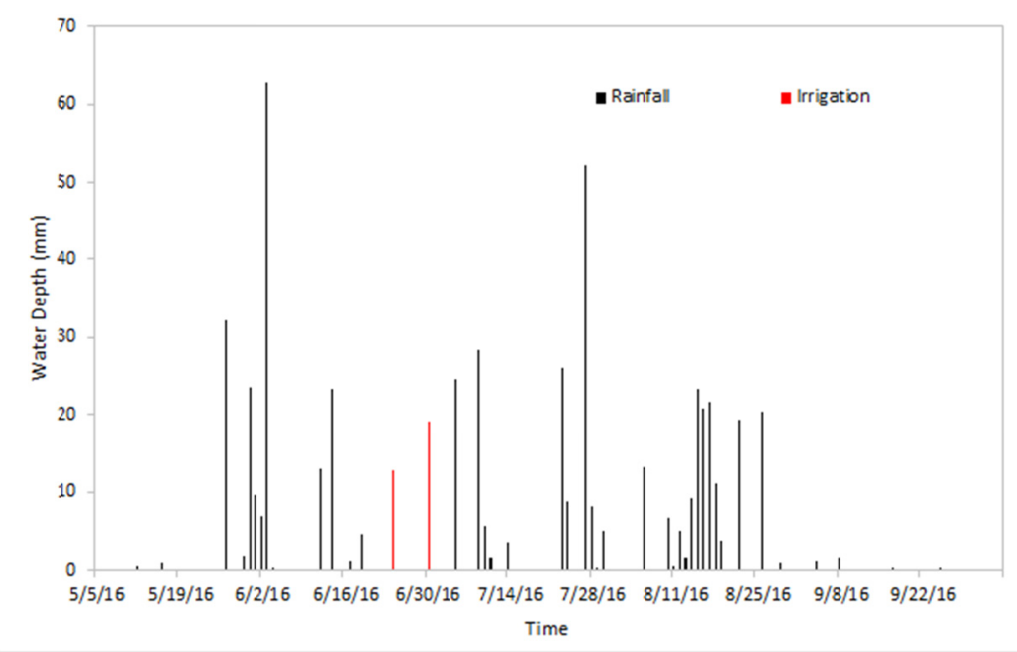

Figure 10. Rainfall distribution and irrigation events in 2016 season

\section{Conclusion}

Soil water content sensors were evaluated for use in irrigation scheduling in cotton. The sensors with wireless data loggers were able to monitor soil-water status, and the sensor measurements could be used as a guidance for irrigation scheduling. The sensors were installed in the predominant soil of the field. The sensors were calibrated with soils from the field where the sensors were installed. In one sensing location, three sensors were installed at depths of $15 \mathrm{~cm}, 30 \mathrm{~cm}$, and $61 \mathrm{~cm}$ for cotton crops. Weighted average method could be used to process the sensor data for soil water content across the crop root zone. Crop root distributions across the root zone and crop growth stages should be considered when the sensor readings at different measurement depths are used to determine a threshold to trigger irrigation events.

\section{References}

Balkcom, K. S., Reeves, D. W., Shaw, J. N., Burmester, C. H., \& Curtis, L. M. (2006). Cotton yield and fiber quality from irrigated tillage system in the Tennessee Valley. Agron. J., 98(3), 596-602. https://doi.org/ 10.2134/agronj2005.0219 
Basal, H., Dagdelen, N., Unay, A., \& Tilmaz, E. (2009). Effects of deficit drip irrigation ratios on cotton (Gossypium hirsutum L.) yield and fiber quality. J. Agron. \& Crop Sci., 195, 19-29. https://doi.org/ 10.1111/j.1439-037X.2008.00340.x

Basinger, J. M., Kluitenberg, G. J., Ham, J. M., Frank, J. M., Barnes, P. L., \& Kirkham, M. B. (2003). Laboratory evaluation of the dual-probe heat pulse method for measuring soil water content. Vadose Zone J., 2, 389-399. https://doi.org/10.2136/vzj2003.3890

Byrd, C. B. (2011). Status of Delta water supplies [PowerPoint slides]. Retrieved from http://www.ymd.org/ $\mathrm{pdfs} /$ deltairrigationmeetings/charlottebyrd.pdf

Chanzy, A., Chadoeuf, J., Gaudu, J. C., Mohrath, D., Richard, G., \& Bruckler, L. (1998). Soil moisture monitoring at the field scale using automatic capacitance probes. Eur. J. Soil Sci., 49, 637-648. https://doi.org/10.1046/j.1365-2389.1998.4940637.x

Cull, P. O., Hearn, A. B., \& Smith, R. C. (1981). Irrigation scheduling of cotton in a climate with uncertain rainfall. I. Crop water requirements and response to irrigation. Irrig. Sci., 2, 127-140. https://doi.org/ $10.1007 / \mathrm{BF} 00257975$

Dukes, M. D., \& Scholberg, J. M. (2004). Soil moisture controlled subsurface drip irrigation on sandy soils. Applied Engineering in Agriculture, 21(1), 89-101. https://doi.org/10.13031/2013.17916

Evett, S. R., \& Parkin, G. W. (2005). Advances in soil water content sensing: The continuing maturation of technology and theory. Vadose Zone J., 4, 986-991. https://doi.org/10.2136/vzj2005.0099

Evett, S. R., Tolk, J. A., \& Howell, T. A. (2006). Soil profile water content determination: Sensor accuracy, axial response, calibration, temperature dependence, and precision. Vadose Zone J., 5, 894-907. https://doi.org/ $10.2136 /$ vzj2005.0149

Fares, A., \& Alva, A. K. (2000). Evaluation of capacitance probes for optimal irrigation of citrus through soil moisture monitoring in an entisol profile. Irrig. Sci., 19, 57-64. https://doi.org/10.1007/s002710050001

Henggeler, J. C., Dukes, M. D., \& Mecham, B. Q. (2011). Irrigation Scheduling. In L. E. Stetson \& B. Q. Mecham (Eds.), Irrigation (p. 495). Irrigation Association, Falls Church, VA.

Leib, B. G., Jabro, J. D., \& Matthews, G. R. (2003). Field evaluation and performance comparison of soil moisture sensors. Soil Science, 168(6), 396-408. https://doi.org/10.1097/01.ss.0000075285.87447.86

Miranda, F. R., Yoder, R. E., Wilkerson, J. B., \& Odhiambo, L. O. (2005). An autonomous controller for site-specific management of fixed irrigation systems. Computer and Electronics in Agriculture, 48(3), 183-197. https://doi.org/10.1016/j.compag.2005.04.003

Pettigrew, W. T. (2004). Moisture deficit effects on cotton lint yield, yield components, and boll distribution. Agronomy Journal, 96(2), 377-383. https://doi.org/10.2134/agronj2004.3770

Seyfried, M. S., \& Murdock, M. D. (2001). Response of a new soil water sensor to variable soil, water content, and temperature. Soil Sci. Soc. Am. J., 65, 28-34. https://doi.org/10.2136/sssaj2001.65128x

Seyfried, M. S., \& Murdock, M. D. (2004). Measurement of soil water content with a 50-MHz soil dielectric sensor. Soil Sci. Soc. Am. J., 68, 394-403. https://doi.org/10.2136/sssaj2004.3940

Sui, R., \& Baggard, J. (2015). Wireless sensor network for monitoring soil moisture and weather conditions. Appl. Eng. in Agric., 31(2), 193-200.

Sui, R., Byler, R. K., \& Delhom, C. D. (2017). Effect of nitrogen application rates on yield and quality in irrigated and rainfed cotton. J. Cotton Sci., 21, 113-121.

Sui, R., Pringle, H. C., \& Barnes, E. M. (2013). Evaluation of soil moisture sensors. Proc. Irrigation Show and Education Conference. Falls Church, VA: Irrigation Association.

U.S. Department of Agriculture (USDA), Economic Research Service. (2017). Cotton and Wool: Overview. Retrieved from https://www.ers.usda.gov/topics/crops/cotton-wool

Vellidis, G., Tucker, M., Perry, C., Kvien, C., \& Bednarz, C. (2008). A real-time wireless smart sensor array for scheduling irrigation. Computer and Electronics in Agriculture, 61, 44-50. https://doi.org/10.1016/ j.compag.2007.05.009

Yao, T., Wierenga, P. J., Graham, A. R., \& Neuman, S. P. (2004). Neutron probe calibration in a vertically stratified vadose zone. Vadose Zone J., 3, 1400-1406. https://doi.org/10.2136/vzj2004.1400 
YMD. (2014). 2014 Water Level Survey. Retrieved from http://www.ymd.org/pdfs/waterlevel/YMD2014Fall WaterLevelSurvey.pdf

YMD. (2015). 2015 fall water level survey result. Retrieved from http://myemail.constantcontact.com/ ymd-joint-water-management-distric.html?soid=1120967545567\&aid=12duw0vcjq4

Yoder, R. E., Johnson, D. L., Wilkerson, J. B., \& Yoder, D. C. (1997). Soil water sensor performance. Applied Engineering in Agriculture, 14(2), 121-133. https://doi.org/10.13031/2013.19373

\section{Copyrights}

Copyright for this article is retained by the author(s), with first publication rights granted to the journal.

This is an open-access article distributed under the terms and conditions of the Creative Commons Attribution license (http://creativecommons.org/licenses/by/4.0/). 